\title{
Nourishing urbanism: a case for a new urban paradigm
}

\author{
Lewis Knight and William Riggs
}

True sustainability demands that we seek to more than 'prop up' traditional approaches to our environment; rather, it requires that we redress current shortcomings in the planning and design of our urban environment at both bio-regional and local scales. Nourishing Urbanism proposes a shift in the urban and non-urban paradigm relating to energy, water and food; all face significant climate-related challenges - and are united by land-use policy, planning and design. We need a renewed planning and design framework for cities and regions that allows the retrofitting of today's urbanity, and prepares our cities for a new tomorrow. Nourishing Urbanism seeks to provide a malleable planning and design framework that embraces the symbiosis between urban and non-urban, and provides for the well-being of the human condition through recommending policies and technical solutions that readdress land use, ultimately impacting the security of our energy, water and soil resources, as well as infrastructure, food supply, health and design.

\section{Introduction}

It was with a sad realization that an 8-year-old girl returned from school confused. She was one of a few children in her class who believed an apple was picked from a tree. Many in her class of budding environmentalists and professionals appeared unaware of the idea of rural and urban interreliance. They believed an apple came from a box at the local supermarket! Luckily, trips to visit rural family had 'fed' her the knowledge that her urban life depended on its relationship with the rural.

Increasingly, the urban (city condition) is isolated from the non-urban (rural, and other), yet ongoing research and documents such as the Millennium Ecosystem Assessment prove their symbiosis is vital to the success of both. The goal of this article is to review the apparent isolation between the urban and non-urban, discuss the trend toward a greater urbanization and its implications for both urban and non-urban constructs, and propose land-use planning and design change.

This article will review urban change and the increasing dominance of the urban condition and, as it becomes more prevalent, how the urban tends to cannibalize the non-urban, resulting in potential failure of both. Utilizing the notion of a basic (biophilic) human need to connect to the natural environment, the article will provide a structural and theoretical basis on which to address issues including energy, water, soil and urban agriculture in a 'nourishing' fashion that reinvents the traditionally separated urban-rural land-use paradigms to promote a more transparent, enriching and ultimately resilient relationship of commonality between the urban and non-urban. The objective is to leverage the dominance of the urban to positively influence its own strength and resilience, and use this dominant role as an agent to reinforce and strengthen the non-urban environment.

\section{The current paradigm}

For many, the paradigm of incompatible urban and nonurban environments is an inescapable and divisive reality. It is reinforced by economies, governments, cultures and history. From the earliest collection of families 
forming small encampments and villages, to our mega-cities of today, the relationship between urban and non-urban has frequently been cast as adversarial. This has not always been the case. An exception to this may be found in the city-states of the Italian Middle Ages. These communities are an example of a more balanced and synergistic relationship between the urban and the non-urban. The non-urban was able to substantially feed the city at its heart. The city provided the opportunity for government, religion, economies and cultures to flourish through interactions, not only inside the city and with other cities, but with the non-urban. However, while this symbiotic relationship between urban and non-urban defined cities in our past, it does not frame our present global urban convention of consumption of non-urban land by the urban.

\section{Contemporary development patterns}

During 2008, the world became largely urban; more than 50 per cent of our six billion population now live in cities. While this is familiar for some, it is a new phenomenon for most (Burdett and Sudjic, 2008). We are part of a great urbanization that shows few signs of slowing. Most global population projections agree that at the end of the $21 \mathrm{st}$ century there will be between eight and 15 billion people on earth, after which population growth may plateau. Of this anticipated growth, the majority will be likely to be absorbed in cities, both existing and new.

This urbanization is a good thing; it promotes interactivity, education, social advances and global human awareness and equity. However, it presents serious environmental challenges that require innovation. As with the demands for urban space, pressures on the environment are also creating a unique paradigm that urban and non-urban are divided despite being coexisting ecosystems. This division between urban and non-urban is of particular concern with regard to overarching environmental issues including climate change, water rights and energy policy.

Development patterns and growth around cities follow a familiar trajectory. In 19th-century London, the planned 'garden cities' became peripheral refuges for the upper and upper-middle classes who commuted to London for work. 'Metroland' was successful as many fled the moral and physical diseases (miasmas) of the inner city for the beauty and purity of the country. Yet the success of these suburbs pressured the greenbelts that were part of their original concept (or design intent) and were intended to connect town with country; and provide all the benefits of country.
After World War II, community design and expansion continued, most frequently outside existing city boundaries (Hall, 1996). Housing construction was encouraged to boost the economy and the transition from military production. These post-war suburbs were populated homogeneously with the middle classes. In the United States, places like Levittown, ex-urban suburbs dependent on private automobiles, became the new urban model (Jackson, 1985). Transportation and commuting patterns reduced the functions of existing and new towns; many became bedroom communities, creating little connection between either urban or rural.

This 'sub'-urban framework produced developments with large-lot homes and dispersed neighbours. While garden suburbs were found to have greater neighbourhood involvement than their urban counterparts, they were largely filled with homogeneous populations which, over generations, created difficulty in social connectedness (Putnam, 2000). Occupants seeking privacy and safety found isolation and social disconnection. Evidence suggests this leads to unhappiness because of the loss of the social capital found in traditional communities.

These 'sprawling' developments have little connectivity on foot. The ease of non-motorized travel to schools, stores and workplaces is limited (Sallis et al., 2004). Further, these activities are often unsafe in communities that were planned for vehicular dominance and built for inactivity. Statistically, suburban residents are more likely to have chronic mental or physical health conditions (Sturm and Cohen, 2004). These development patterns have also contributed to poverty and blight, exemplified in the United States by minorities who are unable to find adequate or healthy housing in inner cities, yet who are unable to afford suburban homes.

This trend away from a more integrated urban model - with interdependence between urban and nonurban - has been recognized as a global phenomenon. It is not one limited to the developed world, and has led to new phrases such as 'edgeless cities' (Lang, 2003). Edgeless cities lack diversity in land use, have inadequate or inaccessible open space, provide limited opportunity for local food production and frequently isolate housing from jobs by not providing transit.

Whether or not sprawl is low density or uncoordinated high density (such as East Asia), the underlying assumption is that, as a phenomenon, it embodies inefficient use of land as a resource. The result continues to be communities that suffer from 'spatial mismatch' and are isolated from the services that support them, placing an unfair burden in allocating resources (environmental and other) on a regional level. 
New Urbanism and Smart Growth (Orinco Station in Portland, Oregon; Poundbury in Dorchester, England; Breakfast Point in New South Wales, Australia) are examples of trends seeking to address issues of ex-urban growth and dispersed urbanism. Both borrow lessons from historic successes and employ more traditional neighbourhood patterns, along with parks and boulevards reminiscent of 19th-century design. However, these 'movements' have largely maintained the pattern of market-based planning and urbanism and, despite claiming to do so, have neither significantly enhanced urban social or environmental equality at a regional scale nor truly provided a 'nourished' urbanism that focuses on the preservation and integration of the non-urban framework.

Whether in the Americas, Europe, Asia or South America, urban success typically leads to horizontal expansion of the city, most often consuming valuable agricultural land at a city's margins to do so. Our challenge is to define an urban paradigm that is healthier, protects our land-based assets more strongly, and supports the ongoing growth and health of our cities.

\section{Global warming and environmental stewardship}

Global warming is one of the key issues that must drive the need to reframe the urban-non-urban paradigm. An Inconvenient Truth raised awareness of global warming at a time when the Kyoto Protocol was not recognized by the incumbent US administration. Yet Al Gore's message requires amplification. MIT researchers estimate that median global temperatures will rise $5.2^{\circ} \mathrm{C}$ by 2100 , double earlier estimates (Sokolov et al., 2009). Three primary issues challenge the resilience of our cities and require assertive environmental stewardship that nourishes urbanism: climatic volatility; sea-level rise and flooding; and change in production systems and methods. During the 2009 bushfires in Victoria, Australia, the ABC reported significant livestock losses. Simultaneously in Queensland, flooding led to herd losses of as much as 50 per cent. While these events are not solely attributable to global warming, they provide a clear indication of potential stock, field and food production losses due to a more volatile climate. This climatic volatility has the potential to produce a more volatile food supply network, with the consequence of greater social and economic instability.

According to the Pew Center on Global Climate Change, flooding at catastrophic levels and sea-level rise has the potential to cause significant inundation of our cities, coastal wetlands and low-lying agricultural lands. The threat of sea-level rise, already being experienced on islands in the Pacific and producing 'environmental refugees', is a significant threat to sustainable agriculture, as many deltas are home to major agricultural production systems. Global warming has the potential to drive significant migration of agricultural production in non-urban areas to portions of the globe once considered unfeasible for crops, thus reinforcing the idea that the urban must carry at least some of this burden. According to a 2007 study, warming temperatures may have reduced the combined production of wheat, corn and barley by 40 million metric tons per year between 1981 and 2002 (Lobell and Field, 2007). The study estimates the annual losses at $\$ 5$ billion. Apart from making a case for the long-term impact of warming on traditional crops, this provides an insight into the potential need to modify crop selection as well as migrate production areas to climatic zones that will, in the future, provide better growing conditions.

\section{An issues-based framework}

While global warming presents an agenda for many, little climate change research investigates the ramifications for land-use planning and design. The interdisciplinary nature of planning and design can, however, become a bridge to environmental activism for both the urban and non-urban.

\section{Energy}

Of the major energy users in land-use terms, transportation and buildings account for the majority of consumption. Adapting to carbon-free energy is critical to defining a resilient future for our cities, both in terms of consumption reduction and migration to true renewability of energy sources. An understanding is evolving of the relationship between transportation infrastructure and land use, and the impact on energy consumption and efficiency, with vehicle miles travelled (VMTs) becoming an index for both.

There has been major change in our product supply network since WWII. Stemming from technological advances and the adoption of the road-rail-ship container, our food industry has become more global, more centralized and more concentrated (Oatkiss, 2005). In the UK, food transport accounted for almost 30 billion vehicle $\mathrm{km}$ in 2002 , producing 8.7 per cent of vehicular $\mathrm{CO}_{2}$ emissions. In the United States, it is estimated that the average grocery store item travels almost 1500 miles $(2400 \mathrm{~km})$ between farm and refrigerator (Thomas and Drukker, 2009). 
Oil, may, in the short term, be replaced by other carbonbased fuel sources, such as coal, natural gas or shale oil that require extraction, or biofuels that require a new balance of land use in non-urban environments. In the longer term, alternative technologies that address climate issues must be allowed to develop.

Irrespective of the replacement of oil, for our urban future to be resilient, we must design for a more frugal short term that protects our environmental assets, while maintaining adaptability to future technologies. The burden of the planning professions is to reduce energy consumption through more compact urban form, while also promoting energy innovations that may require new planning methods.

\section{Water}

Water is also a carrier of disease and pollution, and a resource that is at risk on a global scale. More than 40 years ago, Rachel Carson warned in Silent Spring of the cumulative impact of toxins in our environment; in many cases these were waterborne (Carson, 1962). Recent studies have linked build-ups of various humanmade contaminants (largely pharmaceuticals) with deformed sex organs in Florida alligators, and with polar bears in the European Arctic becoming more hermaphroditic. Equally crucial, as it affects our food systems from fish to larger mammals, is the ability to sufficiently clean pollutants so they do not contaminate food sources (Clover, 2006).

The World Health Organization estimates that almost 884 million people lack access to safe drinking water (United Nations, 2009) while 2.5 billion have no sanitation, leading to increased incidence of disease. In the developed world, declining infrastructure expenditures and facility failure place strain on existing water supplies and sanitation.

Nevertheless, water infrastructure is a significant contributor to the built form of cities. Many of the great cities of the world are located on a waterway, be it an ocean, sea, lake or river. Where water is scarce, as in Bangalore (India) and Las Vegas (USA), growth of the contemporary city is paralleled by construction to ensure water supply. In both cases, the underground aquifer is challenged to meet demand and, in recharge, clean water is often replaced by a more polluted equivalent.

Water infrastructures have formed the basis for major urban renovations within the city. The canals of Amsterdam and St Petersburg were developed to enable city construction. Both the 'modernization' of Paris under Baron Haussman in the mid-1850s, and the construction of London's Embankment during the 1860s, exemplify the pursuit of clean water and sewage leading to great city-making ventures.

Ironically, while our cities are sources of significant point-source pollution, they also have sufficient population and centralization to make them the ideal treatment centres for our waters, both fresh and saline. In essence, our cities will need to adapt to a more systemic relationship with water, becoming the filters of water in the environment, rather than merely consumers then dischargers.

\section{Soil loss and nutrient depletion}

Loss of arable land to production is a significant risk to agriculture systems. In China, 10 per cent of arable land available in 1979 has been lost to rapid urbanization (McKinsey Global Institute, 2009). Should this trend continue, by 2029 a further 15 per cent will be lost to urbanization, or almost 20 million acres. Much of China's urban expansion has occurred in the relatively rich grain bowl in the southeast of the country, potentially exacerbating the loss of high-yield arable land. The Chinese government has identified the loss of productive land as a significant issue, and since 1986 has trialled several mechanisms to maintain minimum arable land values in the nation. The success of these moves will be vital to the country's future as it continues to become more urban.

Loss of soil fertility presents a similar issue. In large part, this is occurring across the globe where new populations either mismanage or deliberately overproduce. For the first time in its history, Egypt has become a net importer of food; it is no longer able to feed itself, as the Nile Valley has become less and less fertile (Montgomery, 2007).

Mismanagement of our productive landscapes, both urban and non-urban, is also a significant issue. Declining agricultural yields, competition for crop space, and continued release of carbon dioxide into our environment due to deforestation all illustrate the misuse of land as a resource.

While other reasons exist for the loss of arable land, historically, the more successful the city, the more voracious its appetite for land. Most typically, the most successful cities are located nearest to their food source and its most fertile soil assets. At issue is a truly sustainable future for ourselves and our planet, one that is not reduced to an equation, and one that recognizes the positive power of the human condition.

\section{Food}

Urban food production is a feature of many cities. In Havana almost 90 per cent of food consumed is 
produced within the boundaries of the city (Viljoen, 2005). The same occurs in Shanghai where the informal sector occupies vacant land to provide a significant portion of the city's daily greens.

Urban food production is not solely a developing world occurrence. Allotments in London arose under the auspices of the House of Lords and were seen as a way (in perpetuity) of attempting to supply cheaper foods for the working class. In Boston, as in London, urban farming developed on a more formal basis when parks were converted to allotments between the World Wars. Urban allotments and gardens have provided a stable yet flexible supply framework, but are now under ever greater pressure of displacement by development, and require greater protection (Viljoen, 2005).

In the United States, local food, slow food and community-supported agriculture are gaining social momentum, and offer opportunities to reinvent a combined urban and non-urban paradigm. However, most focus on 'in-season' food produced on smaller scales without the aid of pesticides or chemicals. The Greenbelt Alliance in San Francisco advocates expanding local food production to the regional park system. These solutions, with others, are being tested by organizations such as the UC Davis Institute of Sustainable Agriculture. There is, however, growing consensus that practices that reduce food miles contain significant environmental benefit. They also support biophilic concepts and can help beautify, enrich and educate urban lives.

Reinstating the criticality of urban agricultural space to feeding and nurturing the public is a key to confronting the growing distance food travels. Alongside a re-education of diets and palates, the environmental and health benefits of eating vegetables and low-food-chain, limited off-gassing meats such as sustainable fish, and the environmental costs of non-urban commodities (fuels, clothing, and building materials) are an integral part of a new urban paradigm that requires responsible land-use policy and planning.

\section{Biophilia (and the human condition)}

We are now faced with a reality in which we are more disconnected and distant from the natural environment within the urban framework, yet we are finding more need for humans to have a connection to the natural world. Roger Ulrich is convincing in his studies of hospitalized patients (Ulrich, 1984). Using the control of a hospital environment, he studied patient recovery rates for those with and without contact to the natural environment. Patients with rooms facing a park had a 10 per cent faster recovery and needed 50 per cent less pain-relieving medication when compared to patients in rooms facing a building wall.

Subsequent research involving those exposed to stress-inducing environments - including hospitals, prisons, offices, military camps and horror films - has indicated in many cases that those with access to greenspace and views of nature have reduced stress reactions (Ulrich et al., 1991). When subjects of such experiments were exposed to natural environments their levels of stress decreased rapidly, whereas during exposure to the urban environment their stress levels remained high or subsequently increased.

While some researchers reference this synergy between the built environment and health as a 'biophilia' hypothesis - the belief that there is an inherent need for connection with nature in every human being (Frumpkin, 2003) - others point to scientific research that concludes that when individuals think about the natural environment the brain is relieved of 'excess' circulation (or activity) and nervous system activity is reduced; thus, stress is relieved (Maller, 2005).

Some contest human reliance on the natural world based on factors such as race and socio-economic status; however, many professions recognize the importance of 'genus locii', 'sense of place' and 'physical beauty'. These require aesthetic or architectural frameworks (including impacts of spatial orientation, memory, passion, and sacred or social constructs) to connect humans with the natural environment. Some studies in the field of psychology suggest that we need to interact with other organisms in addition to the natural environment to reach maturity; and that lack of interaction with nature (living in a 'denatured environment') leads 'to a society of childish adults' (Dekay and O’Brien, 2001).

\section{Land use and buildings as the keystone}

In concurring with 'biophilia' there is a need to emphasize the connection between the built environment and the natural world. However, much urban space continues to be designed and planned, particularly in the developing world, with a consumptive attitude to the non-urban landscape. The idea of integrated natural beauty for agricultural utility and for biophilic benefits is muddied by scientific and sustainability metrics - the engineering-based concept that we should be able to quantifiably measure the benefit of environmental impacts. Correspondingly, the notion of natural beauty for beauty's sake is largely dismissed. Better 
building science that integrates urban agriculture, sustainable transportation and active living environments can help, but the pursuit of natural beauty within the urban framework is equally important, and should become part of the overarching framework by which we measure the success of our cities.

Many studies suggest that urban access to food systems and the natural environment has been compromised. In Los Angeles during 2006 the Rand Corporation found that the majority of the city population was underserved by the park system, and did not have sufficient access to parks and open space to maintain physical activity (Cohen et al., 2006). The study showed that most parks were more than three miles from the residents they served, becoming essentially unusable. When recreational assets at local churches or school yards were close, they were frequently locked and inaccessible during the evenings and weekends when usage would be higher (Scott et al., 2007).

We now understand that connections between land use, transportation and the environment play a large role in food access and a healthy urban experience (Frank, 2000). The act of driving, largely contributed to by urban development patterns, causes stress and mental fatigue (Frumpkin, 2002), and increased driving to buy or transport food and to get to work or play has been correlated to increased in body mass index (BMI), equating to a six per cent increase in the likelihood of obesity (Frank et al., 2004). Further, there are generations of US citizens who face location-based discrimination in their ability to access healthy food (Morland, 2002). Clearly, it makes sense to rethink land use and the urban framework to reduce driving trips and increase access to the natural environment.

If simply 'greening' environments can be both healthy and have climate change impacts, a new emphasis on urbanism that integrates high-performance, highquality green space within the built environment must provide a mechanism for improving our cities. This forms the basis of suggested new directions and a theoretical framework that fuses the urban and non-urban. By nourishing urbanism with the pragmatism and beauty embedded in the natural world we can begin to reinvent and reshape the urban and non-urban paradigm as it currently stands. It calls for practitioners to embrace the non-urban environment as a part of the urban when thinking about the future.

\section{What is the recommendation for our urban context?}

While issues of transportation and the market economy play roles in shaping urban agriculture and open space, there are critical land-use planning, urban design and architecture opportunities that can provide the backbone for nourishing urbanism and address many of the previously identified issues for environmental activism. These opportunities form a baseline for reinventing the urban and non-urban paradigm - a reinvention that starts with some of the basic building blocks of our society, or how we build and develop our land.

\section{Energy}

- Reduce food miles. Efforts should be made to reduce both miles travelled and energy consumed in feeding ourselves. We must be careful that the availability of diverse diets does not continue advancing at the cost of the environment. While biofuelling and alternative vehicles can provide some gains in this arena, a policy which requires a labelling scheme identifying the distance food has travelled and its carbon footprint could reinforce the value (both environmental and market) of local food. This, combined with more efficient transit and a revisitation of how urban land is used for agriculture, could create dramatic reductions in food miles.

- Develop alternate (synthetic) materials suitable for fuel, housing and clothing. Material science will become more essential as we continue to degrade our soils - irrespective of the ability of production land to keep pace with the demand for these materials. Additionally, there is a new generation of synthetic fabrics that are intended to be biodegradable. Many, while artificial, are made from agricultural by-products.

- Incentivize land-use policy that increases access to public transport. Increasing land-use mix to encourage 'active transportation' for trips to local food and services that increase physical activity (Sallis et al., 2006), and encouraging shorter blocks, smaller streets and higher density (Frank, 2005). Density alone is proven to be one of the strongest indicators of walking.

Orinco Station in Portland, OR and Atlantic Station in Atlanta, GA integrate features associated with healthier residents at work and play to encourage walking. These include: increased mix of accessible uses (residential and at least one other use); safety elements such as wider or more sidewalks, pedestrian refuges and trafficcalming measures; providing lanes and parking for bikes; 'more windows facing the street and more street lighting, and fewer abandoned buildings, graffiti, rundown buildings, vacant lots, and undesirable land uses' (Alfonzo et al., 2008, p. 44); reduced incentives 
for driving such as free parking and using the private market to set a value on common resources such as air quality.

Many communities are now using location-efficient loans to encourage greater levels of density in priority development locations, incentivized through reduced interest rates to consumers. In places like the San Francisco Bay Area these loans are being discussed under the regional 'Transportation for Liveable Communities' scheme. Combined with local funding for street-level pedestrian safety improvements, these programmes should increase transit access, not only for transportation purposes but also for the distribution of agricultural and commercial products.

\section{Water}

- Plan for shortage (and tell the story). Greater emphasis should be placed on water as a limited and/or polluted commodity. This must be evident in building codes and development, and must become a feature of the built environment showcasing it. Many architects and planners are showcasing seasonality in the urban landscape, rebuilding/recreating traditional marshes and wetlands, and building networks of 'waterscapes' that restore natural watersheds, passively improve water quality and educate the public about ecosystems. Requiring such features in building codes would create a greater awareness of 'living' water features that are tied to the land and seasonal changes in water supply.

- Footprint all development. Water footprinting should be embraced on a wider scale in development evaluation, and is likely to be used more frequently in California under a recent Assembly Bill. It is proving a reliable method for evaluating global water use. However, trade should be a significant consideration as many water-rich environments bear significant unaccounted burdens by exporting to more arid environments, paying the burden for increased consumption and pollution that occurs as the producing nation (Hoekstra and Chapagain, 2008).

- Zero pollutants. Like calls for zero-carbon or wastefree communities, zero waterborne pollutants must be a goal of all urban areas. Our cities have the resources to clean fully and must do so, to protect downstream populations and environments.

- Mandate on-site water retention and preservation. Options include urban marshes, aquifers and increased water storage and retention areas. In Australia, watersensitive urban design and in the United States, lowimpact development integrate stormwater management and treatment into the urban environment. In the UK, Climate Change Adaptation by Design: a Guide for Sustainable Communities recommends planning mitigation for future changes in water, including regional interventions that include: water storage in existing aquifers; flood attenuation; increased tidal defences and sea walls; and run-off management. Much of this strategy is articulated in projects such as the Adaptable Urban Drainage Project (available at www.k4cc.org/bkcc/audacious).

- Mandate 'clean' aquifer recharge policies. Like many extraction industries, removal of water from aquifers needs to be balanced with clean water recharge. Declining aquifer levels and increased pollutants are causing significant issues globally.

\section{Soil}

- Entitle soil nutrient recharge. Divert waste, and establish nutrient replacement cycles from the urban to the non-urban through both policy and land-use planning. This will potentially be very valuable where urban agriculture is fully integrated into the urban land-use pattern, and is already being developed by the East Bay Municipal Utilities District in Oakland, California, where organic industrial and agricultural waste is being accepted to balance the waste stream, drive an energy plant, and provide clean compost for re-use on agricultural lands.

- Establish valuation of lands that favour long-term productivity. Establish price controls and preservation targets that encourage and support productive land preservation and incentivize life long soil replenishment and management. One way of doing this could be to develop new/more broadly defined economic indices that prioritize net future value and incorporate evidence-based analysis of healthy lifestyles. By incorporating these factors into the economic modelling of development, a more far-reaching understanding of development patterns should be incorporated into urban infill and new developments.

\section{Food}

- Promote regionally based design. Adopt planning and design that is critically regional. Unfortunately, not all environments are equal, and a regional perspective is essential to balance resources and provide for the common good. Local environments require the development of critical responses that are tailored to their situation, rather than the application of normative planning and design principles. Each city region should be planned as a whole, 
protecting food sheds, reducing vehicle miles and generating a balanced attitude to land use and equity.

Agriculture is typically practised on the outskirts of cities in planned greenbelts that surround cities but do not always best serve them. Sweden and Denmark have provided examples of radial areas of greenspace extending from a town centre, connected by rail, bike and pedestrian routes between Malmo and Copenhagen, but this greenspace has focused on space solely for recreation rather than for productive agricultural uses (Hall, 2009). Oft-cited Village Homes in Davis, CA integrate more agricultural space, yet leave out transit infrastructure in favour of the automobile.

A true complete integration of the urban and nonurban should be pursued as a new theoretical framework in the planning, architectural and engineering fields, recognizing a role for the rural greenbelt but integrating non-urban uses within the urban core. Some of these original concepts of 'radiating' greenspace throughout the city lie not in the theory of greenbelt preservationists like Ebenezer Howard and Frederick Olmsted but in modernists like Le Corbusier.

New 'ecotown' concepts planned as new sustainable communities in the UK claim to achieve this, but paradoxically are planned on 'greenfield' sites formerly used for agriculture and grazing. 'The Preserve' in Stockton, CA seeks to provide agricultural land throughout the 1800-acre development which balances water usage and seeks to restrict VMTs.

- Encourage new forms of land preservation and conservation. Through promoting innovative management and design of publicly held land and open space. Berkeley, CA is working with landscape designer Walter Hood to create green, open space corridors through its downtown, and New York City has converted the former High-Line Rail into an elevated urban park. These spaces provide integrated natural space and define a community identity which educates locals about the origins of their food, water, supplies, and their unique place in the natural ecosystem.

- Embrace innovative approaches to increased density that support land preservation, conservation and management for agriculture and open space. Through an integrated regional land-use approach aimed at providing a platform for regenerating and improving the urban and non-urban framework. Examples such as the concept plan for new development at the Napa Pipe project in Napa, CA (near protected Napa Valley wineries) illustrate how new development can knit the urban and non-urban. Homes maximize land-use efficiency to provide significant communal space in the form of shared green open spaces and the preservation of agricultural land; however, even these examples may not go far enough towards achieving true symbiosis between urban and non-urban.

- Establish policy to produce and grow food locally on public land. Many US cities are establishing mandatory urban agriculture programmes that take advantage of vacant lots, rooftops, medians and public open space for food production and education. San Francisco has sent model ordinances to city legislators suggesting that food be produced within the city's border and that city agencies source healthy food from within its foodshed. The city allows public food subsidies to be accepted at farmers' markets.

- Establish minimum maintenance standards for undeveloped land. Land banking and ownership should require a minimum standard of maintenance or production, so that absentee landlords manage land in an appropriate fashion for the broader ecosystem.

- Consider whole-life management practices for public facilities such as schools. Food and nutritional policies should encourage community partnerships, local and organic production, and the requirement of schoolyard gardens to produce organic produce. School programmes are already in place and have been used in Berkeley, San Diego and Philadelphia, positively impacting on educational environments and bringing healthy food options to local schools (Center for Health Improvement, 2006). Although more research is needed, there is anecdotal evidence that such programmes can increase student health and academic performance (Ozer, 2007).

- Promote urban research that verifies innovative mixed-use such as 'vertical agriculture'. Vertical agriculture is becoming more viable and costeffective. It increases the possibility that buildings and agriculture can symbiotically coexist - and opens the possibility that the urban provides not only jobs and housing, but feeds, clothes and nurtures the health of residents.

During a recent exhibition at Ryerson University in Toronto, the prospects of urban agriculture were explored by other disciplines (Carrot City, 2009). Dutch architectural firm MVRDV provided a vertical Pig City, while others explored the possibility of vertical agriculture both as integrated in the built form of skyscrapers, and as a new typology of vertical greenhouse. While potentially more far-reaching in vision, there is significant evidence that these structures may prove a viable form of providing food to the urban some time in the future. 
- Address social equity connections to food and open space resources. Most literature recognizes access to healthy food as an index for decades of segregation and inequality (Williams and Collins, 2001). Socioeconomic status should not mean that one lives without a nutritionally balanced diet, has no access to public and private transportation, is exposed to higher crime, has less retail amenity, and lives with problems such as litter, noxious odours and discarded needles.

The Robert Wood Johnson Foundations' Active by Design programme provides an example that has supported noteworthy, community-based health programmes in cities such as Boulder, $\mathrm{CO}$, Portland, OR, Cambridge, MA, Olympia, WA, and Lexington, KY that have worked to establish healthy habits in local residents (ALBD, 2006). These programmes recommend an ecological approach to chronic diseases such as obesity that focuses on multiple pathways to disease - addressing the built environment at the same time as behaviour. Programmes that embrace this balanced approach should be used to support more equitable access to resources.

- Educate about healthy diet. Diet as a factor relates not only to urban agriculture but to beauty and enrichment for our largely sedentary urban lifestyles. Children in the United States spend over four hours per day in front of the television (Robinson, 1998) and 31 percent of the adult population is obese (American Obesity Association, 2008). Education on nutrition and healthy, low-impact eating should come at the earliest periods, creating sustainable behaviour that lasts a lifetime.

Policies that focus on food preferences have been ineffective in fighting addiction to diets heavy in artificial sugars, large amounts of high-fructose corn syrup (HFCS) and saturated fats. More aggressive policies should be pursued such as the taxation of sodas and junk food, and the clear labelling of sugar additives such as HFCS. Money from these taxes could then be used to subsidize schoolyard gardens, walking to school programmes such as the International Walk to School Day (www.walkto school.org/) and to turn parking spots into green spaces, as happened in the recent PARKing Day (www.parkingday.org/).

\section{Infrastructure}

- Intelligent and unique infrastructure. Roads and urban infrastructure are not specifically part of this article. However, infrastructure, particularly below- ground utilities and roads, is one of the most resilient contributors to urban form. Historically, it has provided an equitable supply of commonly needed resources. In order to manifest Nourishing Urbanism, infrastructure will need to be modified and/or reconfigured to support actions described elsewhere.

- Promote multiple-use/recycling/repurposing of structures. Review building codes which separate uses, and require access and egress that is different for different uses. The elevator has become the freeway of the vertical city - isolating and antisocial. A review of all building codes is required to make construction both simpler and also more adaptable to alternate uses, and more able to accommodate future unforeseen uses such as vertical agriculture.

\section{Design}

- Design is important. Promote a culture of design excellence. Many cities are beginning to realize the economic and social benefits of a well-designed contemporary urban public realm. Frequently, when confronted with social change, communities opt for historicist design responses (new urbanism/neotraditionalism), yet contemporary urban society requires innovation in the urban environment.

- Develop social indexes as measures. Increasingly, planning will need to be more than performancebased; it will need to become evidence-based. Clear indicators against which long-term performance is measured will need to be determined beyond economic productivity of a city or region. Ironically, obesity levels are rising in the United States, China and India. Diet is often cited, yet there is also correlation between increased dispersion of urban services and health concerns. Increased community health, longer life spans, less expensive (and more preventative) medicine, and higher academic achievement will all be achieved, should planning embrace whole-life systems rather than static horizontal consumptive models. These indices must provide a more compelling measurement of the way we plan.

- Research and design new building technologies and materials. Locally source sustainable materials to aid in housing our growing population. These technologies should be offered within the framework of a holistic design that integrates the non-urban and urban ecosystems while being well designed. Many ratings frameworks (LEED, BREAM, GreenGlobes, Build-It-Green) attempt to address sustainable materials but none achieve an 'ecosystems' 
ethos that integrates urban and non-urban. Green building standards should enliven the built environment but not prohibit density and creative, healthy and beautiful urban spaces.

Using observational evidence from other projects, hospital environments are being designed to integrate natural views to improve patient, visitor and staff experiences and connect them to nature. This trend is finding traction in the planning and design community in London through the work on Space Syntax by Bill Hillier, and deserves greater exposure.

- Provide increased access to parks and open space. Access to usable and meaningful open space should be a priority, not only through exactions on developers, but must be incentivized. Despite the environment having health benefits and prolonging lifespan, many communities still have little green or natural space accessible to residents (Takano et al., 2002). There are limited national or international benchmarking standards for local open space policy. In the past a rule of thumb has been 1 acre per 1000 persons; however, few if any cities achieve this.

- Develop operations and management mechanisms that are flexible. Accessible open space in the urban setting is essential for human life and should be addressed directly by international benchmarks and policy at the regional level. Allocations could be made for regional open space accessibility allowing for all populations to have equal access to healthy lifestyle choices and active spaces. These targets could in turn be articulated to regional, state and national decision makers in the hope that the entire urban environment could be "nourished' through regionalism and intergovernmental cooperation.

\section{Conclusion}

We need a new paradigm; a construct that reinvigorates the urban and the non-urban, which evaluates and reframes the professions responsible for planning and design of our environments. We must transform our traditional professional roles and responses. It is time for a new normative framework that turns environmental advocacy into activism. We must integrate the personal and the professional in order to nourish urbanism and hence nourish ourselves and our families. We must not only develop a new and more nuanced way of designing environments that reaches further than previous professions; we must conduct our professional practice, living, working, playing, eating, gardening and greening our immediate environments.

There is a need to reconnect our urban and non-urban environments through a reinvigorated urbanism that fully embraces the notion of healthy environments. Urban land should be fed and, in turn, should nourish the urban condition. It should not only feed us, but clothe us, house us and fuel our mobility with goods, services and agriculture. It should complement and provide beauty and meaning to our time spent walking to school, socializing at friends' houses, going to the library, the store or the park. It should not be sustained as our term 'sustainability' would imply; it should be 'enriched' so that the benefits of the natural world can be felt by all, regardless of age, race, class or creed.

In doing so, we can ensure that our children are not confused about where their food comes from. They will know that apples don't just come from boxes in stores; they are grown in schoolyards, backyards, streets, and unique non-urban, natural places that nourish the urban environment.

\section{References}

ALBD (Active Living by Design) Case Studies, 2006, Robert Wood Johnson Foundation [available at www. activelivingbydesign.org/index.php?id=342].

Alfonzo, M., Boarnet, M. G., Day, K., McMillan, T., Anderson, C. L., 2008, 'The relationship of neighborhood built environment features and adult parents walking', Journal of Urban Design 13 (1), 29-51.

American Obesity Association, 2008 [available at http://obesity1. tempdomainname.com/subs/fastfacts/obesity_US.shtml].

Burdett, R., Sudjic, D., 2008, The Endless City, Phaidon, London. Carrot City, 2009, Carrot City On-line Guide, Ryerson University, Toronto, Canada [available at www.verticalfarm.com].

Carson, R., 1962, Silent Spring, Houghton Mifflin, Boston, MA.

Clover, C. Ch., 2006, The End of the Line: How Fishing is changing the World and What We Eat, University of California Press, Berkeley, CA.
Cohen, D., Sehgal, A., Williamson, S., Sturm, R., McKenzie, T. L., Lara, R., Lurie, N., 2006, Park Use and Physical Activity in a Sample of Public Parks in the City of Los Angeles, RAND Corporation, Santa Monica, CA [available at www.rand.org]. Center for Health Improvement, 2006 [available at www.cahpf. org/GoDocUserFiles/130.Case\%20Studies\%205.3.06.pdf].

Dekay, M., O’Brien, M., 2001, 'Gray city, green city', Forum for Applied Research and Public Policy 16 (2), 19-27.

Frank, L. D., 2000, 'Land use and transportation interactions: implications on public health and quality of life', Journal of Planning Education and Research 20, 6-22.

Frank, L. D., Andresen, M., Schmid, T., 2004, 'Obesity relationships with community design, physical activity, and time spent in cars', American Journal of Preventive Medicine 27 (2), 87-96.

Frank, L. D., Schmid, T., Sallis, J., Chapman, J., Saelens, B., 2005, 'Linking objectively measured physical activity with objectively measured urban form findings from SMARTRAQ', American Journal of Preventive Medicine 28 (2). 
Frumpkin, H., 2002, 'Urban sprawl and public health', Public Health Reports May-June (117), 208.

Frumpkin, H., 2003, 'Healthy places: exploring the evidence', American Journal of Public Health 93, 1451-1456.

Hall, P., 1996, Cities of Tomorrow, Blackwell Publishers, Oxford.

Hall, P., 2009, 'Lecture at UC Berkeley College of Environmental Design', 25 September.

Hoekstra, A. Y., Chapagain, A. K., 2008, 'Globalization of water: sharing the planet's freshwater resources. The global component of freshwater demand and supply: an assessment of virtual water flows between nations as a result of trade in agricultural and industrial products', Water International 33 (1), 19-32.

Jackson, K., 1985, Crabgrass Frontier: The Suburbanization of the United States, Oxford Press, New York.

Lang, R., 2003, Edgeless Cities, Brookings Press, Washington, DC

Lobell, D. B., Field, C. B., 2007, 'Global scale climate-crop yield relationships and the impacts of recent warming', Environmental Research Letters 2.

Mauer, C., 2005, 'Healthy nature healthy people: "contact with nature" as an upstream health promotion intervention for populations', Health Promotion International 21 (1), 48.

McKinsey Global Institute, 2009, Preparing for China's Urban Billion, Research Report (pp. 398-412) [available at www. mckinsey.com/mgi/publications/china_urban_summary_of_ findings.asp].

Montgomery, D. R., 2007, Dirt - The Erosion of Civilizations, University of California Press, Berkeley, CA.

Morland, K., 2002, 'Neighborhood characteristics associated with the location of food stores and food service places', American Journal of Preventive Medicine 22 (1), 23-29.

Oatkiss, P., 2005, The Validity of Food Miles as a Sustainability Indicator, DEFRA Report, UK.

Ozer, E., 2007, 'The effects of school gardens on students andschools: conceptualization and considerations for maximizing healthy development', Health Education Behavior 34, 846-864.

Putnam, R., 2000, Bowling Alone, Touchstone, New York, 327-335.

Robinson, T., 1998, 'Does television cause childhood obesity', Journal of the American Medical Association 279, 959-960.
Sallis, J., Frank, L. D., Saelens, B. E., Kraft, M. K., 2004, 'Active transportation and physical activity: opportunities for collaboration on transportation and public health research', Transportation Research A 38, 249-268.

Sallis, J., Cervero, R. B., Ascher, W., Henderson, K. A., Kraft, M. K., Kerr, J., 2006, 'An ecological approach to creating active living communities', Annual Review of Public Health 27, 297-322.

Scott, M. M., Cohen, D. A., Evenson, K. R., Elder, J., Catellier, D., Ashwood, J. S., Overtona, A., 2007, 'Weekend schoolyard accessibility, physical activity, and obesity: the Trial of Activity in Adolescent Girls (TAAG) study', Preventive Medicine 44, 398-403.

Sokolov, A. P., Stone, P. H., Forest, C. E., Prinn, R., Sarofim, M. C., 2009, 'Probabilistic forecast for 21 st century climate based on uncertainties in emissions (without policy) and climate parameters', Journal of Climate 169 [available at http:// globalchange.mit.edu/files/document/MITJPSPGC_ Rpt169.pdf].

Sturm, R., Cohen, D., 2004, 'Suburban sprawl and physical and mental health', Public Health 118, 488-496.

Takano, T., Nakamura, K., Watanabe, M., 2002, 'Urban residential environments and senior citizens' longevity in megacity areas: the importance of walkable green spaces', Journal of Epidemiology and Community Health 56, 913-918.

Thomas, J., Drukker, C., 2009, 'Returning to their roots', Urban Land Institute Supplement Spring, 43-47.

Ulrich, R., 1984, 'View through a window may influence recovery from surgery', Science 224, 420-421.

Ulrich, R. S., Simons, R. F., Losito, B. D., Fiorito, E., Miles, M.A., Zelson, M., 1991, 'Stress recovery during exposure to natural and urban environments', Journal of Environmental Psychology 11, 201-230.

United Nations, 2009, Millennium Development Goals Report (p. 47). United Nations, New York.

Viljoen, A., (ed.) 2005, Continuous Productive Urban Landscapes. Designing Urban Agriculture for Sustainable Cities, Architectural Press, London.

Williams, D., Collins, C., 2001, 'Racial residential segregation: a fundamental cause of racial disparities in health', Public Health Reports 116, 404-416.

Williams, R., 1975, The Country and the City, Oxford University Press, Oxford. 